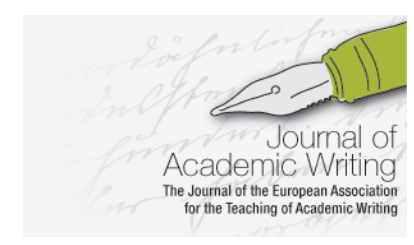

Journal of Academic Writing

Vol. 8 No 2 Winter 2018, pages 137-149 http://dx.doi.org/10.18552/joaw.473

\title{
'Aargh! This Essay Makes Me Want to Poke Sticks In My Eyes!' Developing a Reader Engagement Framework to Help Emerging Writers Understand Why Readers Might (Not) Want to Read Texts
}

Sarah S. Haas

Ghent University, Belgium

\begin{abstract}
This paper outlines the development of the "Reader Engagement framework", a tool for helping emerging writers understand what might keep readers reading - or stop readers from reading - a text. The Reader Engagement framework has been under development for the past five years, primarily in the context of undergraduate English proficiency classes at a large university in Flanders. Using the principles of constructivist grounded theory (Charmaz 2014), a preliminary framework was sketched using as data the margin comments of one reader who noted points of engagement or disengagement while reading student texts. Additional rounds of data collection included the engagement perceptions of student-readers, as well as those of teacher-readers from various disciplines. Thus far 1087 readers have been consulted, and the categories in the framework seem to be largely saturated. Though further refinement is necessary, the framework has been found successful as a teaching tool, and as an assessment and feedback tool. It also seems to have potential for offering writers a new way of conceptualising writing.
\end{abstract}

\section{Introduction}

This paper presents the development of a Reader Engagement framework (RE framework), a tool for helping emerging writers conceptualise their responsibilities as writers. I will start by defining some relevant terms, and giving an overview of the research context. After explaining the inception of the framework, I will go on to describe the methodology for data collection and analysis. The result of the analysis - the RE framework itself - will be presented, and relevant/interesting highlights discussed. After acknowledging limitations, I will outline ways in which the framework has thus far been successful, before pointing to further development and future research.

To start from a point of clarity, I begin by giving definitions of terms that are used: text, reader engagement, and disengagement. I also distinguish between engaging text and engrossing text.

While recognising that the term "text" has taken on various lay meanings, and that, in a linguistic sense, text can be either written or spoken (Trask and Stockwell 2007: 312), I use the term here to indicate written work done by students for a university course. The texts that were analysed for this study were short (500-2500 words) works of fiction, creative non-fiction, or academic essays written in English. As such, any findings are intrinsically limited. 
Two uses of the term "reader engagement" can be found in the literature: a narrow meaning, from the perspective of the writer, and a broader meaning, from the perspective of the reader. In the broader sense, from the reader's viewpoint, engaging text 'encourage[s] [an] audience to at least continue reading' (Hyland 2005c: 21). Here, engagement can be seen as the reader feeling engaged in the text.

The more specific use of the term, from the writer's perspective, is as one component of metadiscourse - the non-propositional commentary on a text that guides a reader and signals the presence of an author (Amiryousefi and Rasekh 2010, Hyland 2017). ${ }^{1}$ In his 2002 model of metadiscourse in academic texts, Hyland regards reader engagement as the writer using linguistic devices to build rapport or interact with the reader, for example by using inclusive firstperson pronouns (Hyland 2002: 7). This use of engagement can be seen as the writer attempting to engage with the reader.

For this paper, I use a broad meaning from the reader's perspective defining "engagement" as a reader's feeling that they are willing to start reading, and continue reading a text - or at least find it relatively easy to start and continue reading. "Disengagement", on the other hand, is readers having the feeling that they want to stop reading a text. The wanting-to-read, and wanting-to-stop focus on the construction of the text itself, rather than on reasons related to content, or to external factors (such as a reader being tired).

To avoid potential misunderstanding, a distinction between "engaging" and "engrossing" is necessary. A text can be engaging (a reader being willing to read), while not necessarily being engrossing (a reader staying up all night to finish a book, for example). Most academic texts are probably not engrossing, but they ought to be reasonably engaging. "Reasonably engaging" is defined by one participant in this study as a text that '[readers are] able to get through without want[ing] to poke sticks in [their] eyes'.

The main reason for pointing out this distinction is to aid the expectations of emerging writers. Expecting to be able to write engrossing texts might not be reasonable, but expecting to achieve engaging texts certainly is. At the very least, it is desirable for student writers to know that their teachers might not expect to be engrossed, but would like to be engaged in the texts they have to read. Indeed, the impetus for this study was my own disengagement in the student texts I was reading.

\section{Context and Research Question}

In February of 2012 I found myself the sole teacher of some 300 Flemish undergraduate students. My task was, in 15 contact hours, to help these just-out-of-secondary-school students write academic texts in English. Though daunting, the task did not seem impossible. The level of English in Flanders is generally very high; these students were English majors, with language levels above the already-high average. Additionally, most of them reported having had some writing instruction in high school, so I thought it would be a simple matter of helping them find interesting topics, reminding them of some rules, and sending them on their way. To get a general idea of which writing rules might need reminding, I started the semester with a diagnostic assignment that was not necessarily academic in nature: students were given 500 words to write whatever they chose, within the fairly loose parameters of traditional fiction (not post-modern), creative non-fiction, or essay. Most students briefly discussed their plans with me before they wrote and submitted assignments.

Seeing the stack of 300 completed assignments was rather intimidating, but I was not necessarily dreading the task: I had confidence in the students' abilities, and had signed off on topics. Furthermore, I am, after all, a reader: I had read the 270,000 words of the first three Harry Potter books in three days (calling in sick to work to finish the third one). Surely it would not take more than a week to read the 150,000 words that were piled on my desk. I approached the pile with no small amount of good will.

${ }^{1}$ For a thorough definition of metadiscourse, please see Hyland 2017. 
Roughly five assignments in, however, the dread began: When I dared approach my desk at all, I found myself flipping through texts, trying to find ones that I could get myself to even start reading. Then, flipping more, I tried to find ones I could keep reading, rather than abandoning after a few sentences. Most days, getting through three or four essays required the use of selfbribery in the form of chocolate, or something stronger. After three weeks of dread and bribes, and the writing not being returned to students, I realised I needed to approach the "Pile" in a different way - as a researcher with a puzzle to solve.

My lack of engagement with these texts puzzled me. Even though the large number of students in my care made it impossible to interact much individually, the students and I had what I thought was a good rapport, and I had been anticipating getting to know them a little more through their writing. It also appeared to me that some elements - good language skills and good ideas - were in place, and this would make for pleasant reading. In spite of these elements being present, however, pleasant reading was not the case.

The topics of the texts made no difference to whether or not I wanted to read. There were texts on topics with which I was not particularly thrilled (the Eurovision song contest); but I found these no more unreadable than topics I was expecting to enjoy (Harry Potter as a bad friend). What was it about these texts, I puzzled, that was making me dread reading them? What was causing me to not even want to pick some of them up, to want to cast aside many of the ones I had actually started reading?

The existing literature on reader engagement did not fully answer my questions. The bulk of recent research examines reader engagement in the narrow sense, from the perspective of academic writers. Texts are analysed with a narrow focus on specific linguistic devices which writers use to try to directly engage with readers (see for example, Ansarinn and Tarlani-Aliabdi 2011, Hyland 2001, 2002, 2005a, 2005b. Hyland and Jiang 2016, Hyland and Tse 2005, Khajavy, Asadpour and Yousefi 2012, Mori 2017). There is very little research that examines engagement from the reader's perspective, in the broader sense of keeping a reader reading. Hyland does interview readers (for example, in 2005b) but they talk generally about writing rather than pinpointing specific points of (dis)enagement in texts. Morton and Storch (2018) do examine readers' perceptions of "voice" in PhD theses; however, this necessarily narrow focus explained only a small part of my own disengagement in the undergraduate texts. Jacob et al. (2018) undertook a high-tech study using eye-tracking, blink-rate, and pupil dilation to estimate readers' (dis)engagement in literary texts and newspaper articles, but they were concerned primarily with where readers were (dis)engaged, not why.

Thus, what was offered in the literature was, for my purposes, incomplete: I sought a general overview of engagement, from the reader's perspective, on texts that were varying in genre. Though not sure gaining such an overview was feasible, I nevertheless decided to step outside the boundaries of pre-existing knowledge (Silverman 2005: 78) and start with a clean slate. I approached the pile with the broad research question 'What is it that is causing me be engaged in, or (more often) disengaged from, these texts?'

\section{Method}

Wanting to approach the texts without using existing frameworks, yet realising the project would strictly be situated in my classes, I opted for the principles of Constructivist Grounded Theory (Charmaz 2014, Charmaz and Bryant 2016: 348-350, Silverman 2005: 179). Taking this inductive approach, I started viewing the texts from the standpoint of "reader", rather than "writing teacher".

\section{First round of data collection and analysis}

To help wipe the slate, and step out of the role of writing teacher traumatised by the "Pile", I assigned myself the role of "good-willed reader": a reader who approaches a text with an attitude that $\mathrm{s} / \mathrm{he}$ wants to read it. This contrasts with the reader whose main purpose is finding fault (as we teachers who are marking too often do), or the weary reader prepared to be disappointed (as I had become). It was only from this standpoint of willingness-to-read, I 
reasoned, that I might be able to actively notice when I wanted to read the texts, and why; and also be able to pinpoint specific places where my willingness to read wavered, and why.

I indicated my willingness by putting checkmarks $(\checkmark)$ next to chunks of text that read smoothly. Backslashes $(/)$ were used to indicate points in the text where I felt my willingness faltered. With each checkmark or backslash, I scribbled margin comments wherein I attempted to explain precisely what it was in the text that was keeping me engaged, or what was interfering with my engagement. After ten or so essays, the checkmark system indicating engagement remained unchanged; the backslash method had evolved to include three increasing levels of disengagement:
I= being slowed down as a reader
$/ /=$ wanting to stop reading, but continuing to read anyway
$I / I=$ stopping reading

In all, 303 student texts were read for engagement, generating a reasonable corpus of some 2000 margin comments.

In Grounded Theory fashion, along with reading, and writing the explanatory margin notes, I used sticky notes - on a wall which had been cleared for the purpose - to make analytic memos comparing and categorizing the margin notes (Cresswell 2013: 85). I zigzagged back and forth between data collection and analysis: every 50 essays or so, I re-arranged the stickies on the wall according to the margin comments and memos I had made. By the end of the 303 texts, I had a preliminary organisation of the reasons for my (dis)engagement. There were two main categories, each with two sub-categories (please see Figure 1).

\begin{tabular}{|c|c|c|c|}
\hline \multicolumn{2}{|c|}{$\begin{array}{l}\text { Initial Engagement } \\
\text { reader feels they want to pick up a text } \\
\text { and start reading }\end{array}$} & \multicolumn{2}{|c|}{$\begin{array}{l}\text { Continuing Engagement } \\
\text { reader feels they want to } \\
\text { keep reading a text }\end{array}$} \\
\hline LOC components & HOC components & LOC components & HOC components \\
\hline $\begin{array}{l}\text { Easy for a reader to } \\
\text { pinpoint reasons for } \\
\text { (dis)engagement; easy } \\
\text { for a writer to facilitate } \\
\text { these components of } \\
\text { engagement, or to repair } \\
\text { disengaging parts of text }\end{array}$ & $\begin{array}{l}\text { More difficult for reader } \\
\text { to pinpoint these reasons } \\
\text { for (dis)engagement; } \\
\text { more difficult for writer to } \\
\text { facilitate these } \\
\text { components of } \\
\text { engagement, or to repair } \\
\text { disengaging parts of text }\end{array}$ & $\begin{array}{l}\text { Easy for a reader to } \\
\text { pinpoint these reasons } \\
\text { for (dis)engagement; } \\
\text { easy for a writer to } \\
\text { facilitate these } \\
\text { components of } \\
\text { engagement, or to repair } \\
\text { disengaging parts of text }\end{array}$ & $\begin{array}{l}\text { More difficult for reader } \\
\text { to pinpoint these reasons } \\
\text { for (dis)engagement; } \\
\text { more difficult for writer to } \\
\text { facilitate these } \\
\text { components of } \\
\text { engagement, or to repair } \\
\text { disengaging parts of text }\end{array}$ \\
\hline
\end{tabular}

Figure 1. Preliminary Categories of Reader Engagement.

A main theme permeating my memos and margin comments was my perception that the responsibility for my engagement as reader lay not entirely, but largely, with the writer. I, as a reader with a lot to read, felt it was the writer's job to get me interested enough in a text to want to pick it up and start reading. After I had begun, I felt it was the writer's job to ensure I wanted to keep reading until the end of the text - or at the very least, to make it easy for me to keep reading. Thus, at the highest over-arching level, the writer is responsible for two categories of reader engagement:

1) "Initial Engagement" is what I call the readers' feeling that they want to pick up a text and start reading in the first place;

2) "Continuing Engagement" is how I describe readers' feeling of, having started a text, actually wanting to continue to the end (or at least not actively wanting to stop).

Within both Initial and Continuing Engagement, there were elements that were easy, as a reader, to pinpoint and explain. These components would be equally easy for writers to implement, or to fix if they were identified as lacking. These "easy" components corresponded 
with what writer developers ${ }^{2}$ call 'Lower Order Concerns' or LOCs ${ }^{3}$ (Thomas, Williams, and Case, 2014). There were also elements that were more difficult for a reader to pinpoint, and would take writers more time and brain energy to implement or fix. These components, which cognitively challenge both reader and writer, corresponded to Higher-Order Concerns (HOCs). Thus, the second level of engagement were the HOC and LOC components of Initial and Continuing engagement.

This first round of data collection and analysis gave me a fairly clear overview of my own engagement as a reader, and I was happy that I was able to name as "(dis)engagement" the problem I had with the texts. There remained the mystery, however, as to why the students who reported choosing to study English because they themselves loved reading and/or writing - had produced such texts. Perhaps what I had identified was my engagement, which may be completely different from other readers. It could very well be that the students would find their texts perfectly engaging. There was only one way to find out.

\section{Second round of data collection: The students}

The second round of data were collected in conjunction with peer feedback activities. Students were asked to be "good-willed readers", and to use the backslash/checkmark system to note places in peers' texts where they wanted to keep reading, or were slowed down. In order to be most helpful to their fellow writers, they were asked to explain, via margin comments, why they were inclined, or not, to keep reading.

Approximately 1500 usable student comments were collected. When asked for permission to use these for research purposes, five students felt uncomfortable, so theirs were discarded. Also discarded were comments that were merely descriptive ('this is confusing') or based on emotion ('I'm bored here'), but offered no reasons why it was confusing, or why the reader was bored. The remaining comments were analysed in the same way as mine, on the same stickynote wall.

The students' engagement, and points of disengagement, did not differ much from mine. The same elements of Initial and Continuing Engagement were present, as well as HOCs and LOCs. There were two major differences, however. The first difference was not surprising: students concentrated on LOCs more than HOCs. They reported that this was because LOCs were 'more obvious' and because '[they] were [accustomed to] having [their] writing checked for [...] grammar, spelling and stuff'. The second difference was of more interest: when they did identify them, students experienced the same HOC issues I had, but they used different language to describe them. The illuminating example of this was my note of 'intersentencial relationship unclear' corresponding to a student's 'what is the link between [these sentences]?'.

In this round of analysis, I started breaking down HOCs and LOCs into their constituent elements, paying particular attention to the language used by students and me. The similarities in engagement, but difference in language, made me curious regarding what other teacherreaders who were not writer-developers might contribute to the understanding of reader engagement.

\footnotetext{
${ }^{2}$ While I realise that the common term is writing developers, I prefer to put the emphasis on the person, rather than on the product or the process.

${ }^{3}$ As the data collection expanded to readers outside the writer development discipline, I started referring to LOCs and HOCs as Lower- and Higher-Order Components, which might not be entirely felicitous with the literature, but it became necessary due to a misunderstanding of the word 'concern': Rather than seeing 'concerns' as a set of more-or-less established features (see for example The Online Writing Lab at Purdue (OWL), or University of Nevada Writing Center), readers outside the discipline sometimes construed 'concerns' to be personal preferences or priorities. For example, one reader remarked that since 'grammar is important to me, for me it's my higher-order concern that [writers] get their grammar and spelling right'.
} 


\section{A third round of readers: Teachers}

I enlisted the help of colleagues in various disciplines (Linguistics, Physics, Economics, Engineering). The student texts being read were similar to my original samples in that they came from first-year undergraduate students. They differed, however, in length and content: these were longer texts (1000-2500 words) and were academic in nature.

It was not practical for teachers to use the checkmark/backslash system in addition to their own marking rubrics, so we agreed they would audio-record themselves thinking aloud as they read the student texts: they would periodically comment on how inclined they were to start reading, keep reading, or stop reading, and to give reasons for their (dis)engagement.

Teacher-reader comments were transcribed and the content analysed using the same stickynote wall and tentative framework. It was found that the categories of Initial Engagement, Continuing Engagement, HOCs and LOCs upheld. The language the teachers used to describe their (dis)engagement was more similar to students' language than it was to mine. The similarity in the teachers' and students' language was interesting enough, but of more interest was the addition that was made to the framework (please see Figure 2).

\begin{tabular}{|c|c|c|c|}
\hline $\begin{array}{c}\text { Initial Engagement } \\
\text { Get the reader to want to start reading } \\
\text { Or at least cultivate the good will of the } \\
\text { reader }\end{array}$ & HOCs & $\begin{array}{c}\text { General Writer } \\
\text { Attitudes }\end{array}$ \\
\hline $\begin{array}{c}\text { Ensure the reader wants to keep reading } \\
\text { Or at least make it easy for the reader } \\
\text { to keep reading (avoid making the reader } \\
\text { want to stop reading) }\end{array}$ & & $\begin{array}{c}\text { (A reader's perception } \\
\text { of a writer's attitude } \\
\text { can affect both initial } \\
\text { and continuing } \\
\text { engagement) }\end{array}$ \\
\hline
\end{tabular}

Figure 2. Engagement framework with the addition of writer attitude.

What emerged from the teacher-reader data was a more solid view of the responsibility readers feel that writers have, and how readers might make unfavourable assumptions about a writer's attitude or intelligence if these responsibilities are not met. Although this feeling of writerresponsibility was present in my own data, and to some extent in student-readers', the teacherreaders made it more explicit. Comments on laziness and stupidity were not uncommon. One of the participants pointed out that this could be due to how the data were collected: knowing that their comments would not be heard by writers set readers free to 'let loose on frustrations [...] I would never write "this makes me want to poke sticks in my eyes" on a student text, but now I could voice what I really felt, and not worry about it'.

Thus, some strong reader beliefs were uncovered, and the category of "Writer Attitudes" was added to the framework, expanding it to include features of Reader Engagement that exist outside the text. A reader's Initial, or Continuing, engagement might waver, for example, if they perceive a writer 'doesn't care about the writing, and certainly not about [the reader]'. On the other hand, If the reader 'trusts [that] a writer has [a reader's] best interests in mind, [the reader] is likely to read with good will.'

\section{Additional data over several years}

This has been 'slow research' (Lillis 2010). Since the inception of the project in 2012, 22 sets of data have been collected and analysed. For the past three years, students' reflective writing has been added as a data source. Although the general components of the framework seem to be saturated (nothing new has been added for over two years), what is still being refined is how the components can be broken down into their constituent elements, what relationships lie 
among them, and most importantly, what language might best be used for optimum accessibility to non-specialist users.

\section{Results and Discussion}

Although I am sure it is not yet finished, the framework in its current state is presented to students in table form (please see Fig. 3), as well as in an alphabetical list of "building blocks of engaging text" (please see Fig. 4). While a complete discussion of all components of the framework is beyond the scope of this article (an annotated glossary is under construction, and will be available via creative commons), I will address some insights emerging from the data which may interest writer developers. I will also touch on ways in which the framework has tentatively been found to be useful.

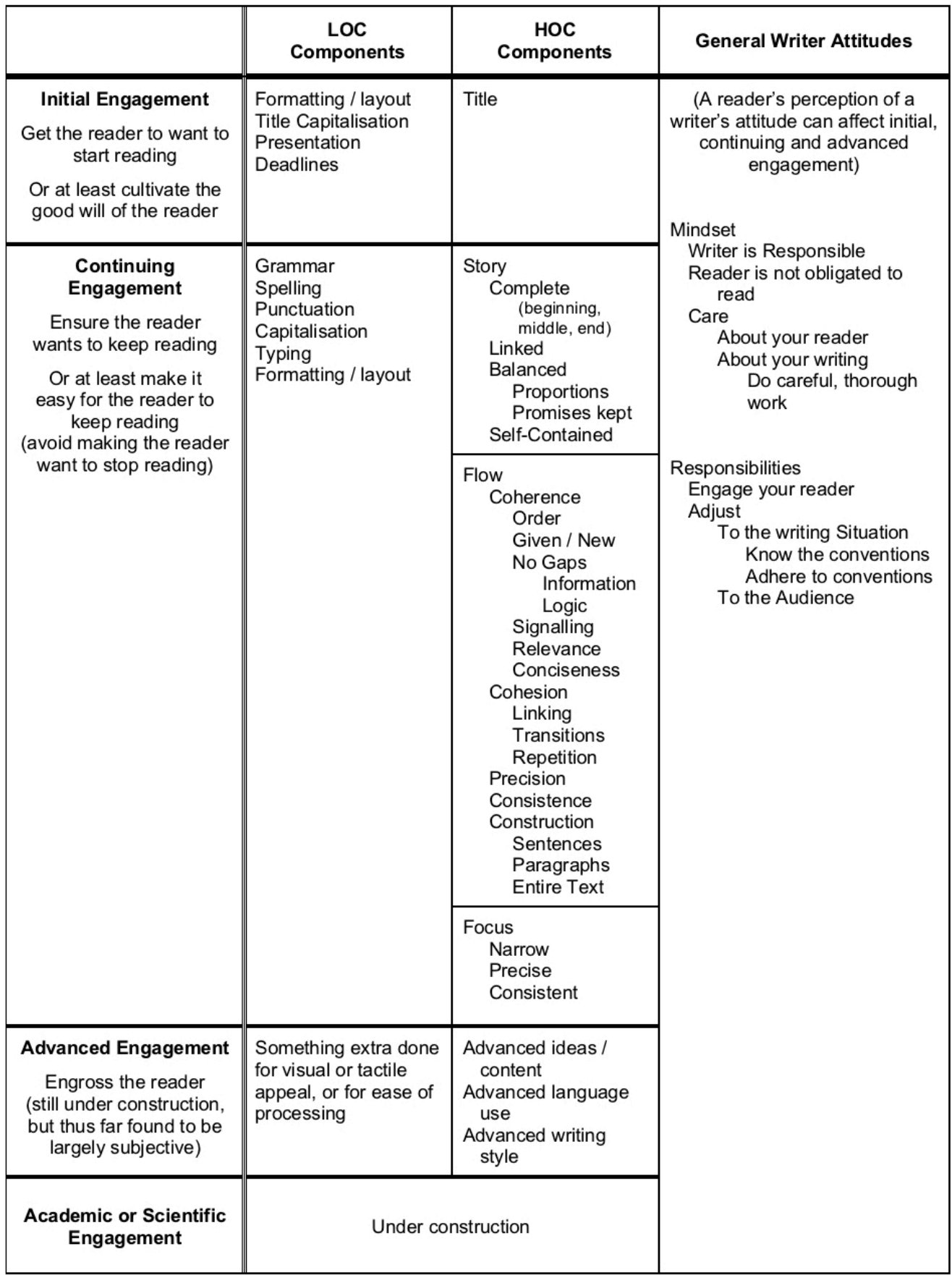

Figure 3. Reader Engagement Framework (thus far). 


\section{The Building Blocks of Engaging Text}

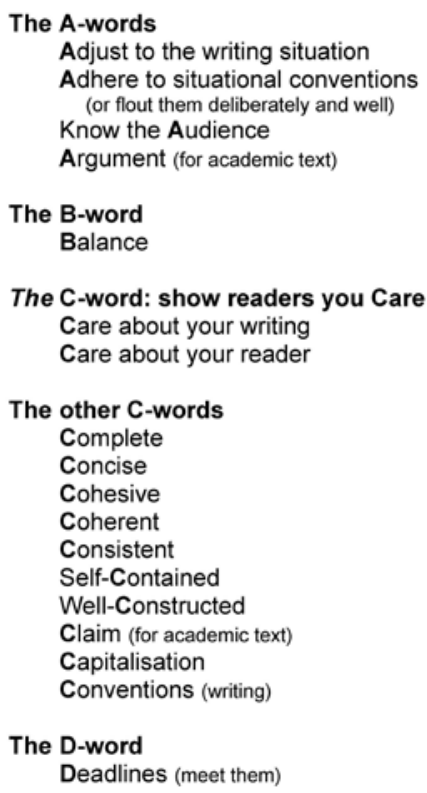

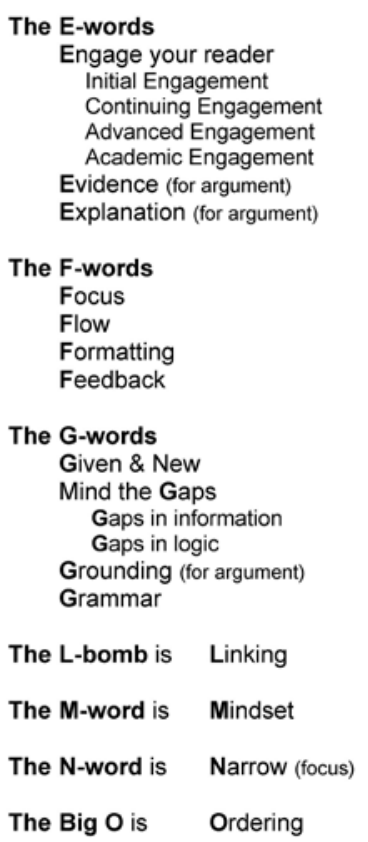

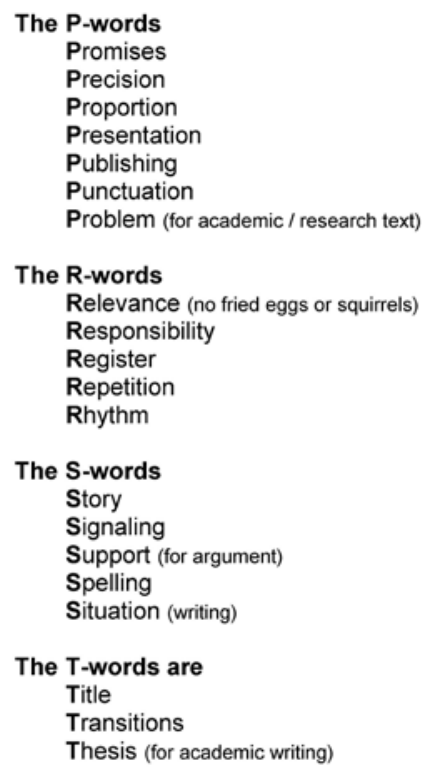

Figure 4. Reader Engagement Framework Components in Alphabetical List.

\section{Points of interest}

Initial engagement starts before the title or first line

For 25 odd years of teaching, I have erroneously advised young writers that they can 'catch a reader' by their title and their first line of text. Although a title is indeed part of Initial Engagement, what has also become apparent via teachers' audio recordings is that Initial Engagement starts (or stops) well before a reader picks up a text. Teachers sifting through a stack of texts 'trying to find one [they] can stand to start reading' is related not only to the title, but also to the way texts are presented visually.

The visual aspects of written work are linked to a reader's perception of writer attitude: 'Is it asking too much that an essay looks nice when I get it?! If [the writer] doesn't care about their writing, why on earth should I?'. Also affecting Initial Engagement was how well readers perceived the writer to have considered reader needs. Texts presented without page numbers, for example, or that were not fastened together, caused aspersions to be cast on the writers' characters:

[The writer] is just so lazy. Page numbers are not difficult. If I happen to drop these, am I meant to start piecing them back together in the right order? And seriously. Buy a stapler.

\section{LOCs and "reader rage"}

Reader perceptions of a writer's care(lessness) affect not only Initial, but also Continuing Engagement. Data indicate that readers are disengaged mid-text for three main reasons: because they are confused, because the text takes too much work for them to process, or because they are annoyed. Confusion and too-much-work are largely HOC-related. Annoyance, on the other hand, is largely due to readers' perceptions that a writer is being sloppy on 'things that are not even difficult'. This can lead to what I started calling "reader rage", where a reader gets so annoyed with LOC issues that they become angry, and thus disengage from the texts.

That most reader rage is LOC-related contrasts sharply with a (mis)conception found in students' reflective writing. Many believe that because LOCs are easy, they are less important, and that readers will be forgiving, provided the content or writing style is good. Contrary to 
students' hopes, teacher-readers, and many student readers, were not inclined to overlook LOCS in favour of recognising genius. Rather, because they are easy, if LOCs are not in order, readers are quick to form unfavourable opinions about the intelligence of the writer, or to lose trust in the writer: 'How stupid can [they] be? If [they] can't even get capitalisation right, how am I supposed to trust anything [they] say?'.

\section{Objectivity and subjectivity}

Not all readers were enraged by LOC issues. One teacher-reader, in line with student expectations, did concentrate more on content and style than on what she called 'mechanics'. This difference in reader priorities was found across HOCs and LOCs. Some readers were annoyed by some issues but not by others. For example, one reader largely overlooked spelling or grammar mistakes, 'unless there were so many it got annoying', but was intolerant if the order of information in a text was confusing. In direct contrast, another reader reported that 'grammar mistakes [...] [are] the biggest buzzkill ever', but was not bothered by a slightly skewed order 'as long as [they] could still piece it together'. This difference in reader preferences could potentially shed light on what is perceived to be subjectivity in writing quality.

Students' reflective writing indicated a belief that 'writing can't be judged because it's so subjective'. The research of Gillioen (2015), who used the RE framework as a basis for a rating scale, however, showed consistency across readers in identifying HOC and LOC issues, which could indicate there is reasonable objectivity. Subjectivity might lie, not in the presence or absence of engagement components, but rather in how much emphasis individual readers put on different components. It could thus be important for writers to know they cannot assume any reader will let anything go, and they must, therefore, get everything right.

There are features of text that do not have a right or wrong. In texts where no HOC or LOC issues were identified, readers reported different levels of 'liking' the text based on content or style. Although more research is needed, it could be possible that, assuming basic engagement components are attended to, being engrossed in a text (what I call "advanced engagement") could be entirely subjective.

\section{Text (dis)engages readers more than content}

One final point of interest is that readers might be more (dis)engaged by how text is constructed than by the content of the text. Teachers lamented that some essays had 'such great ideas, but [they] just [weren't] readable without screaming'. A student who was invested in non-profit organisations was surprised to find that reading the newsletters of these organisations disengaged him almost immediately, contrary to his expectations of being engrossed (De Soete 2017).

\section{Tentative successes so far}

Along with revealing interesting characteristics about readers and writers, there is some evidence that the RE framework might be of use to readers and writers, both in my own context, and slightly beyond.

\section{Student writing is better}

The first indication of usefulness is that the texts I now read seem so much better than the ones in that first pile. Drafting this article has been done in conjunction with reading 220 essays from students who have been introduced to the RE framework. Of these 220, only five have been, as a colleague has started calling it, 'sticks-in-eyes-inducing'. Although reading so many texts is still tiring and time-consuming, it is no longer unpleasant. I do not need nearly as many bribes.

\section{Users find the framework useful}

Even more gratifying than my reduced chocolate intake is that students themselves, according to their reflective writing, find the RE framework useful, viewing it as 'a toolbox [they] can use to make [their] texts better'. Along with students, teachers who have become familiar with the framework have reported that it helps them 'pinpoint what is wrong - or right! - about a [text]' and then enables them to 'explain it without always defaulting to spelling and grammar'. The perceived usefulness of the framework is related to two themes in the data: first, the framework 
uses 'language that actually means something [to users]', and second, the framework gives users 'a new way of looking at writing'.

An example of (in)accessible language, are the words 'cohesive' and 'coherent' which were used by nearly half the readers in this study. These concepts have been examined by researchers for years (for example, Coulthard 2016, Halliday and Hasan 1976, Redeker 2000). While researchers have deconstructed both coherence and cohesion, these concepts remain 'fuzzy [...] and difficult to teach and learn' (Lee 2002: 135). One problem for non-specialists is that the breakdown of the concepts is, as one student wrote, 'phew! Too difficult! Can anyone explain [what these are] in language that actually means something?' While the RE framework is certainly not as precise as other treatments of complex concepts (for an overview of how coherence has been conceptualised by different researchers, see Lee 2002: 139), what it might offer is a more intuitive breakdown, presented in the language of the users themselves, rendering it more useful, if less precise. As noted in the reflective writing of one student, 'with the help of these building blocks C-words, I can finally putting (sic) my finger on why [this text] doesn't flow the way I think it should'.

Aside from being a practical toolbox, the framework might also be useful conceptually, giving writers a new way to think about writing, writers and readers. Many students reflected on never having thought much about being a writer in the first place, about having writerly responsibilities, or about having a reader. The collective reflections were summarised beautifully by one student:

I never thought of myself as a true writer. I finished assignments, but I wasn't writing, I was just 'doing homework'. I never thought about a reader. I doubt my classmates ever did. Now I feel sorry for my [high school teachers].

To see if the uses might extend beyond the original context, I have offered the framework to $\mathrm{PhD}$ students in the hard sciences who were seeking to improve their texts. When later asked if they found the framework useful, the responses have been enthusiastic, with one replying, 'Hell, yes. I keep that thing pinned above my desk. I use it to structure everything.' Another reflected, 'It has changed the way I think about writing and about me as a writer. I never felt before that I could call myself a writer. Now I do'.

\section{Limitations and Further Research}

While these successes are indeed encouraging, they can only be considered tentative, as there has never been more than one degree of separation from me. This means that the framework, its potential successes, and the research that has produced it, all have limitations. It also means that there is more research required to validate these tentative findings and successes.

$\mathrm{PhD}$ candidate enthusiasm notwithstanding, the first limitation is that the framework has been developed using primarily the writing of first-year undergraduates. Although De Soete (2017) has shown the framework's cross-genre and cross-language potential, more work is needed to see how transferable the framework is to other genres, other languages, or other levels of writing experience.

The second limitation is that, while the framework might use intuitive language, it is also less precise than other frameworks for analysing text. The RE framework currently has overlapping components (signalling, linking, and promises, for example) that do not have the concrete definitions found in other models of cohesion (for example, Halliday and Hasan 1976). It may be that these overlaps are desirable in the interest of non-expert readers being able to quickly and intuitively 'put a finger on what is [(dis)engaging] about a text', but I am not yet comfortable with the lack of precision.

Furthermore, while users might find the framework relatively intuitive, not all the components are immediately obvious. Neither is it immediately natural for readers to notice precisely where 
in a text they are engaged or disengaged, or to be able to explain why. Thus, potential users need explanation and training before the framework can be optimally put to use.

Finally, due to the subjective nature of reader preference, it would be impossible to give writers a recipe for engaging every reader. However, it might be useful for future study to examine how components of the framework are "weighted" by readers. If there are components that are generally regarded by readers to be more important, writers would be able to focus their attention to those particulars.

\section{Conclusion}

Box (1979) comments that all models are wrong, but of more interest is whether they are illuminating and useful. This is, I think, applicable to this RE framework. While far from "right", it can be considered both illuminating and useful. It is wrong because the data are limited; because some components are less precise than what is already available; because would-be users face a steeper learning curve than I would like. However, the development of the model illuminated some important insights about engagement from the readers' perspective, which have thus far been under-examined. The framework can also be considered useful, because non-expert users have found it intuitive enough to consult when structuring their own texts, or pinpointing what they "feel is off" about other texts. I do believe, however, that the greatest potential value of this framework is a general picture of "Engagement" from the reader's perspective, which might give fledgling or reluctant writers a new way to think about writing; a reminder to think about their readers; the permission to consider themselves true writers. Perhaps that is what we all need from time to time. 


\section{References}

Amiryousefi, M., and Rasekh, A. E. (2010) 'Metadiscourse: Definitions, Issues and Its Implications for English Teachers'. English Language Teaching 3 (4), 159-167

Ansarin, A. A., and Tarlani-Aliabdi, H. (2011) 'Reader Engagement in English and Persian Applied Linguistics Articles'. English Language Teaching, 4 (4), 154-164

Box, G. E. P. (1979) 'Robustness in the Strategy of Scientific Model Building'. in Robustness in Statistics. ed. by Launer, R. L, and Wilkinson, G. N. New York: Academic Press, 201236

Charmaz, K. (2014) Constructing Grounded Theory. 2nd edn. London: Sage Publications

Charmaz, K., and Bryant, A. (2016) 'Constructing Grounded Theory Analysis'. in Qualitative Research. 4th edn. ed. by Silverman, D. London: Sage Publications, 347-362

Coulthard, M. (ed.) (2016) Advances in Written Text Analysis. New York: Routledge

Creswell, J. W. (2013) Qualitative Inquiry and Research Design: Choosing Among Five Traditions. Thousand Oaks, CA: Sage Publications

De Soete, A. (2017) Reader Engagement in the Non-Profit Sector: Designing, Implementing, and Evaluating a Newsletter Writing Course for NPO Workers. Unpublished Master's Dissertation. Ghent: Ghent University

Gillioen, T. (2016) Writing Mentors Guiding Student Writers: Evaluating Mentoring Efficacy Through Student Reflection and Essay Analysis. Unpublished Master's Dissertation. Ghent: Ghent University

Halliday, M. A. K., and Hasan, R. (1976) Cohesion in English. London: Longman

Hyland, K. (2001) 'Bringing in the Reader'. Written Communication 18 (4), 549-574

Hyland, K. (2002) 'Directives: Argument and Engagement in Academic Writing'. Applied Linguistics 23 (2), 215-239

Hyland, K. (2005a) 'Representing Readers in Writing: Student and Expert Practices'. Linguistics and Education 16 (4), 363-377

Hyland, K. (2005b) 'Stance and Engagement: A Model of Interaction in Academic Discourse'. Discourse Studies 7 (2), 173-192

Hyland (2005c) 'Patterns of Engagement: Dialogic Features and L2 Undergraduate Writing'. in Analysing Academic Writing: Contextualized Frameworks. ed. by Ravelli, L., and Ellis, R. London: Continuum, 5-23

Hyland, K. (2017) 'Metadiscourse: What Is It and Where Is It Going?'. Journal of Pragmatics $113,16-29$

Hyland, K., and Jiang, F. (2016) "'We Must Conclude That...": A Diachronic Study of Academic Engagement'. Journal of English for Academic Purposes 24, 29-42

Hyland, K., and Tse, P. (2005) 'Hooking the Reader: A Corpus Study of Evaluative that in Abstracts'. English for Specific Purposes 24 (2), 123-139 
Jacob, S., Ishimaru, S., Bukhari, S. S., and Dengel, A. (2018) 'Gaze-based interest detection on newspaper articles'. in Bulling, A., Kasneci, E., and Lander, C. (eds.) PETMEI '18: Proceedings of the 7th Workshop on Pervasive Eye Tracking and Mobile Eye-Based Interaction. held 14-17 June SWPS University of Social Sciences and Humanities, Warsaw. New York: Association for Computing Machinery

Khajavy, G. H., Asadpour, S. F., and Yousefi, A. (2012) 'A Comparative Analysis of Interactive Metadiscourse Features in Discussion Section of Research Articles Written in English and Persian'. International Journal of Linguistics 4 (2), 147-159

Lee, I. (2002) 'Teaching Coherence to ESL Students: A Classroom Inquiry'. Journal of Second Language Writing 11 (2), 135-159

Lillis, T. (2010) The Value of Local Research for Sustaining Writing Development in Higher Education: The Case of 'Academic Literacies'. [keynote lecture] Writing Development in Higher Education Conference. held 28-30 June at the Royal College of Physicians, London

Mori, M. (2017) 'Using the Appraisal framework to Analyze Source Use in Essays: A Case Study of Engagement and Dialogism in Two Undergraduate Students' Writing'. Functional Linguistics [online] 4 (1), 1-22. available from <https://link.springer.com/content/pdf/10.1186\%2Fs40554-017-0046-4.pdf> [15 October 2018]

Morton, J., and Storch, N. (2018) 'Developing an Authorial Voice in PhD Multilingual Student Writing: The Reader's Perspective'. Journal of Second Language Writing, 1-9

Redeker, G. U. (2000) 'Coherence and Structure in Text and Discourse'. in Abduction, Belief, and Context in Dialogue: Studies in Computational Pragmatics. ed. by Bunt, H., and Black, W. Amsterdam: John Benjamins, 233-164

Silverman, D. (2005) Doing Qualitative Research. $2^{\text {nd }}$ edn. London: Sage Publications

The Online Writing Lab at Purdue (n.d.) Welcome to the Purdue OWL. [online] available from $<$ http://owl.english.purdue.edu/> [30 November 2017]

Thomas, M., Williams, A., and Case, J. (2014) 'The Graduate Writing Institute: Overcoming Risk, Embracing Strategies, and Appreciating Skills'. The Learning Assistance Review 19 (1), 69-98

Trask, R. L., and Stockwell, P. (eds.) (2007) Language and Linguistics: The Key Concepts. 2nd edn. Abingdon: Routledge.

University of Nevada Writing and Speaking Center (n.d.) HOC and LOC. [online] available from<https://www.unr.edu/Documents/liberal-arts/writing-center/HOC-LOC Comments(0).pdf> [6 November 2017] 